\title{
Developmental outcome in newborn infants treated for acute respiratory failure with extracorporeal membrane oxygenation: present experience
}

\author{
K Khambekar, S Nichani, D K Luyt, G Peek, R K Firmin, D J Field, H C Pandya
}

See end of article for authors' affiliations

Correspondence to

Dr Pandya, Department of ECMO and Paediatric Intensive Care, Glenfield Hospital, Groby Road, Leicester LE3 9QP, UK ; hp28@le.ac.uk

Accepted 16 July 2005 Published online first 13 September 2005

\begin{abstract}
Objective: To describe the later health status of newborn infants who received extracorporeal membrane oxygenation (ECMO) for acute respiratory failure in the era after the UK ECMO trial.

Design: Prospective follow up study of newborn infants who received ECMO at a single centre between January 1997 and January 2001.

Setting: Departments of ECMO and Paediatric Intensive Care, University Hospitals of Leicester.

Patients: All babies who received ECMO within 14 days of birth.

Interventions: Neurodevelopment screening using the schedule for growing skills-II (SGS-II) assessment tool.

Main outcome measures: Survival at 12 months of age by disease and functional development at follow up.

Results: A total of 145 neonates received ECMO for treatment of respiratory failure. Of these, 108 (75\%) were alive at 1 year of age. There were no deaths in children treated for respiratory failure secondary to meconium aspiration syndrome (73/145). Ninety three (86\% of survivors) infants attended a follow up visit at 11-19 months postnatal age. Eighty two were classed as normal, seven as having "impairment", and four as having "severe disability".

Conclusions: Most newborn infants with acute respiratory failure treated with ECMO will have a normal neurodevelopment screening assessment at 11-19 months of postnatal age. There is no evidence to suggest that changes in neonatal practice since the UK ECMO trial have led to changes in outcome of infants undergoing ECMO therapy.
\end{abstract}

$\mathrm{T}$ e UK collaborative ECMO trial firmly established extracorporeal membrane oxygenation (ECMO) for treating respiratory failure in newborn infants. ${ }^{1-3}$ Although the treatment phase of the trial has finished, survivors are regularly assessed to determine long term neurological outcome. The results of the follow up programme at 1 and 4 years indicate a favourable prognosis for most infants treated with ECMO. ${ }^{4}$

At the time of the UK ECMO trial, access to treatments such as inhaled nitric oxide (iNO) and high frequency oscillatory ventilation (HFOV) were limited, and surfactant therapy was not often used to treat severe meconium aspiration syndrome (MAS). ${ }^{1-3}$ However, since the ECMO trial, access to iNO and HFOV has increased, and surfactant therapy is now used to treat MAS. ${ }^{5-8}$ Therefore it is possible that newborns referred for ECMO therapy in the present era have a different severity of respiratory disease at the point of referral. Consequently, such infants may have different neurological outcomes from those reported in the UK ECMO trial. Over the last decade, the Heartlink ECMO centre at Glenfield Hospital has treated nearly 400 infants with ECMO. In 1997, we began to prospectively follow up all infants treated with ECMO in order to determine later health status. This report details survival and neurological outcomes for newborn infants who have received ECMO at our centre between January 1997 and January 2001.

\section{METHODS}

\section{Case identification}

The names of all babies who received ECMO aged less than 14 days at Glenfield Hospital between January 1997 and January 2001 were obtained from an in house database.
Patient details (basic characteristics, diagnosis, treatments before ECMO, and outcome after ECMO) were retrieved from the case records.

\section{Developmental assessment}

Neurodevelopment was determined at 11-19 months of age using the schedule for growing skills-II (SGS-II), a widely used screening tool ${ }^{9}$ which assesses development in 10 "skill" domains (active and passive posture, locomotor, manipulative, vision, speech and hearing language, interactive and self care social, cognitive). SGS-II is based on the Sheridan developmental sequences and has been validated against Griffiths mental developmental scales. ${ }^{9}$ Its forerunner was used in the UK national child encephalopathy study.' All children were examined by either KK or HP, and in five cases by both, to ensure that the tool was used in a consistent manner.

\section{Data analysis}

Individual skill domain and overall developmental quotients (DQs) for each child were calculated by dividing "achieved" individual and overall scores by mean scores for the child's age range (10-11, 12-14, 15-17, and 18-23 months). Children who were blind or deaf and/or had an overall DQ score $<50 \%$ predicted were concluded to have "severe

Abbreviations: $C D H$, congenital diaphragmatic hernia; $D Q$, developmental quotient; ECMO, extracorporeal membrane oxygenation; HFOV, high frequency oscillatory ventilation; iNO, inhaled nitric oxide; MAS, meconium aspiration syndrome; Ol, oxygenation index; PPHN, persistent pulmonary hypertension of the newborn; SGS-II, schedule for growing skills-II 


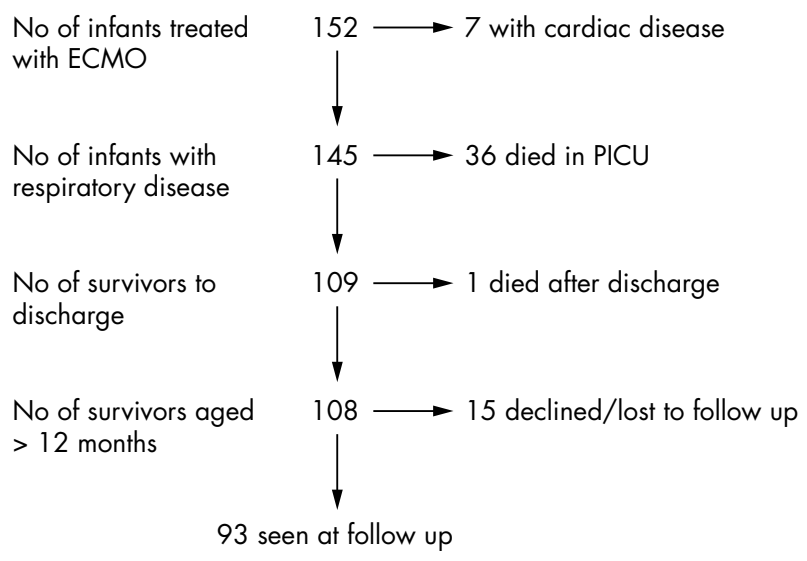

Figure 1 A flow diagram detailing the outcome of neonates referred for and treated with extracorporeal membrane oxygenation (ECMO) between 1997 and 2001 inclusive at Glenfield Hospital, Leicester. PICU, Paediatric intensive care unit.

disability", whereas children with overall DQ scores of 50$69 \%$ predicted, or a locomotor DQ of less than $70 \%$ predicted, or were receiving regular anticonvulsants, or needed tube feeding, or required oxygen were concluded to have "impairment". Children with an overall DQ greater than $70 \%$ predicted were classed as "normal". Comparisons of the present data with UK ECMO trial data were made using a $\chi^{2}$ test for dichotomous data. $\mathrm{p}<0.05$ was considered significant.

\section{RESULTS}

Between January 1997 and January 2001, 152 newborn infants aged less than 14 days received ECMO therapy in our unit (fig 1). Seven infants with heart lesions were excluded. Tables 1 and 2 list data and details of the remaining 145 infants.

The mean oxygenation index (OI), a marker of disease severity, was 51 , but nearly a third of infants had an OI $<40$ at referral, 40 being the traditional criterion for ECMO referral. Before ECMO therapy, most infants were receiving or had received a variety of other treatments (table 1). Comparing the UK ECMO trial cohort with our data (table 1) shows significantly greater use of these treatments and a greater proportion of referrals within 24 hours of birth in the current era.

Twelve month survival for the cohort was $75 \%$. Although no deaths were recorded in infants with MAS, 36 infants died
Table 2 Outcome of the 152 infants less than 14 days of age who received extracorporeal membrane oxygenation (ECMO) at Glenfield Hospital between 1997 and 2001

\begin{tabular}{lll}
\hline Diagnostic category $(\mathbf{n = 1 5 2 )}$ & $\begin{array}{l}\text { Survivors } \\
(\mathbf{n}=110)\end{array}$ & $\begin{array}{l}\text { Non-survivors } \\
(\mathbf{n}=\mathbf{4 2})\end{array}$ \\
\hline $\begin{array}{l}\text { Congenital heart disease } \\
\text { Respiratory disease }\end{array}$ & 2 & 5 \\
$\begin{array}{l}\text { Seen at follow up ( } \mathrm{n}=93) \\
\text { Meconium aspiration }\end{array}$ & 108 & 37 \\
Idiopathic PPHN & 65 & 0 \\
$\quad$ Sepsis (group B streptococcus) & $9(5)$ & 9 \\
$\quad$ Congenital diaphragmatic hernia & 3 & 12 \\
$\quad \begin{array}{l}\text { Alveolar capillary dysplasia } \\
\text { Surfactant protein B deficiency }\end{array}$ & 0 & 4 \\
Declined/lost to follow up ( $\mathrm{n}=15)$ & 0 & 2 \\
$\quad$ Meconium aspiration & 8 & 0 \\
Idiopathic PPHN & 3 & 0 \\
Sepsis (group B streptococcus) & $4(2)$ & 0 \\
\hline
\end{tabular}

Values in parentheses are percentages.

PPHN, Persistent pulmonary hypertension of the newborn.

in hospital and one child with congenital diaphragmatic hernia $(\mathrm{CDH})$ died after discharge. A third of non-survivors had $\mathrm{CDH}$. Six other babies had untreatable respiratory conditions. Figure 1 and table 2 give the details.

Tables 3 and 4 and fig 2 give the health status of the 93/108 children assessed. The mean overall DQ score for the group was 105. Mean group scores for individual skill domains varied between 92 (cognitive) and 119 (locomotor). Data for active and passive posture domains are not shown, as nearly all children received maximum scores in these skills. Eighty two children were classed as normal, seven as having impairment, and four as having severe disability. No infant was blind, totally deaf, or receiving oxygen therapy. All four children with severe disability had overall and locomotor DQ scores of less than 50 and additional health problems such as squint and tube feeding. One had trisomy 21 . Four of seven children with impairment had DQ scores $<70$ in the locomotor skill domain. One of them also required a hearing aid. The three other children with impairment were receiving supplemental feeding. Figure 2 is a scatter plot showing individual locomotor skill domain DQ scores. Four children with DQ scores in the normal range had squints. Although the status of the 15 infants who did not receive follow up is uncertain, contact with families and correspondence from referring units suggest that none of these children have severe health problems.

\begin{tabular}{|c|c|c|c|}
\hline & $\begin{array}{l}\text { Glenfield } \\
(n=145)\end{array}$ & $\begin{array}{l}\text { UK ECMO trial } \\
(n=63)\end{array}$ & p Value \\
\hline \multicolumn{4}{|l|}{ Oxygenation index } \\
\hline $\begin{array}{l}\leqslant 40 \\
>40\end{array}$ & $\begin{array}{l}42(29) \\
103(71)\end{array}$ & & - \\
\hline Mean oxygenation index & 51 & 63 & 0.05 \\
\hline \multicolumn{4}{|l|}{ Age at ECMO } \\
\hline$<24 \mathrm{~h}$ & $70(48)$ & $23(37)$ & NS \\
\hline $24-48 \mathrm{~h}$ & $44(31)$ & $23(37)$ & NS \\
\hline$>48 \mathrm{~h}$ & $31(21)$ & $17(26)$ & NS \\
\hline \multicolumn{4}{|l|}{ Therapies before ECMO } \\
\hline Pulmonary vasodilators excluding iNO & 57 (39) & $54(86)$ & $<0.01$ \\
\hline iNO & $65(45)$ & $5(8)$ & $<0.01$ \\
\hline Inotrope & $110(75)$ & $50(79)$ & NS \\
\hline HFOV & $77(53)$ & $4(6)$ & $<0.01$ \\
\hline Muscle relaxant & $121(83)$ & $54(86)$ & \\
\hline Surfactant & $116(80)$ & $16(25)$ & $<0.01$ \\
\hline
\end{tabular}

Values in parentheses are percentages.

iNO, Inhaled nitric oxide; HFOV, high frequency oscillatory ventilation. 
Table 3 Development quotients (DQs) for eight of the 10 skill categories in the schedule for growing skills-II (SGS-II) developmental assessment tool for infants who received follow up after extracorporeal membrane oxygenation (ECMO) at Glenfield Hospital

\begin{tabular}{ll}
\hline Skill domain & DQ \\
\hline Locomotor & $119(36)$ \\
Manipulative & $109(21)$ \\
Visual & $100(21)$ \\
Speech and language & $97(26)$ \\
Hearing and language & $101(25)$ \\
Interactive social & $112(36)$ \\
Self care social & $108(34)$ \\
Cognitive & $92(31)$ \\
Overall & $105(29)$ \\
By type of ECMO & $100(30)$ \\
Venoarterial & $105(22)$ \\
Venovenous & \\
\hline Values are mean (SD) (n = 93). &
\end{tabular}

\section{DISCUSSION}

The main findings of this report are that survival for newborn infants with severe acute respiratory failure treated with ECMO is excellent and that most survivors are normal on developmental screening at 11-19 months. However, data from other follow up programmes, including that for the UK collaborative ECMO trial, indicate that a full picture regarding the health status of these children will not emerge until later. ${ }^{4}$

Survival $(75 \%)$ to 1 year of age for newborns receiving ECMO in the study period is in line with other ECMO programmes and better than reported by the UK collaborative ECMO trial group..$^{1-3}{ }^{10-12}$ Infants who died could be divided into a group with congenitally abnormal lungs and a group with normal lungs at birth. Idiopathic persistent pulmonary hypertension of the newborn (PPHN) and sepsis were the only two diagnostic categories in the latter. The group with congenitally abnormal lungs included infants with $\mathrm{CDH}$, alveolar capillary dysplasia, and hereditary surfactant protein $\mathrm{B}$ deficiency. All infants with $\mathrm{CDH}$ were referred for ECMO therapy before surgical repair. Only a few could be weaned from ECMO support on to mechanical ventilators despite early surgical repair of the hernia and a prolonged ( $>2$ weeks) ECMO run. The disappointing survival for infants with $\mathrm{CDH}(3 / 15)$ is indicative of the severe lung dysplasia present in some children with this disorder, and it is our view that outcome for this subgroup of infants with $\mathrm{CDH}$ is unlikely to improve in the absence of an effective "lung growth" strategy, with or without ECMO.
Survival for infants with MAS was $100 \%$, a finding that has been reported by other ECMO programmes. ${ }^{10-12}$ These observations show that ECMO is a very effective treatment for MAS. Moreover, the data show that zero or near zero mortality is an achievable goal for this disorder. One reason for the excellent survival statistics for MAS may be a general improvement in the care of infants with hypoxaemic respiratory failure. For example, compared with the UK ECMO trial, present day infants were referred earlier in the course of their illness and were more likely to have received treatments known to improve oxygenation, such as surfactant, iNO, and HFOV. It is therefore possible that these treatments, in conjunction with early institution of ECMO, resulted in present day infants having less prolonged and/or profound episodes of hypoxaemia-ischaemia than infants in the UK ECMO trial. The net result is the excellent survival figures for MAS. It is noteworthy that, despite the greater use of surfactant, iNO, and HFOV before ECMO, there was no significant difference in the time of referral for ECMO. This is also encouraging as there had been concern that a strategy of ECMO avoidance, where possible, might result in late referral of a number of infants. The only evidence of such an effect is the $21 \%$ of babies whose referral still occurs after 48 hours.

Comparison of the current outcome data with UK ECMO trial data ${ }^{2}$ shows more children in the severely disabled category in the present day cohort (even after accounting for the child with trisomy 21 who would have been excluded from the UK ECMO trial), but fewer children with impairment. There are several possible explanations for these differences. Firstly, the better survival rate for the present day cohort compared with the UK ECMO trial equates to about 10 more infants being alive at follow up. These "extra" survivors may have been those most likely to have disability. Although it could be argued that compared with the UK ECMO trial, infants in the present era were less sick (lower OIs) and had a shorter period of postnatal hypoxaemiaischaemia (earlier referral), neither the time to ECMO referral nor a lower OI correlate with better outcomes. ${ }^{1-4}$ Differences in assessment methodology may also explain the disparity in developmental outcomes. More specifically, as SGS-II is a screening tool designed to detect definite "normality" and definite "abnormality", it has little sensitivity for detecting subtle abnormalities. Thus DQ scores above 100 do not indicate above average development, and few children are likely to have DQ scores in the "impairment" range. A third possible explanation is that the missing data on 15 infants have distorted the pattern of results. Finally, the age of assessment may also have distorted the findings, as the UK ECMO trial data show that it is important that follow up continues at least until school age.

Table 4 Developmental outcome for infants who received follow up $(n=93)$ by disease and type of extracorporeal membrane oxygenation (ECMO) run

\begin{tabular}{lllll}
\hline & Total & $\begin{array}{l}\text { No with severe } \\
\text { disability }\end{array}$ & $\begin{array}{l}\text { No with } \\
\text { impairment }\end{array}$ & No normal \\
\hline All infants & 93 & $4(5)$ & $7(8)$ & $82(87)$ \\
CDH & 3 & 0 & 1 & 2 \\
MAS & 65 & 3 & 5 & 57 \\
Idiopathic PPHN & 16 & 1 & 0 & 15 \\
Sepsis & 9 & 0 & 5 & 73 \\
Venovenous & 81 & 3 & 1 & 9 \\
Venoarterial & 11 & 1 & $16(26)$ & $45(73)$ \\
UK ECMO trial & 62 & $1(1)$ & 0 & 9 \\
\hline
\end{tabular}

Developmental outcome for infants in the UK ECMO trial are listed for comparative purposes. Numbers in parentheses are percentages.

$\mathrm{CDH}$, Congenital diaphragmatic hernia; MAS, meconium aspiration syndrome; PPHN, persistent pulmonary hypertension of the newborn. 


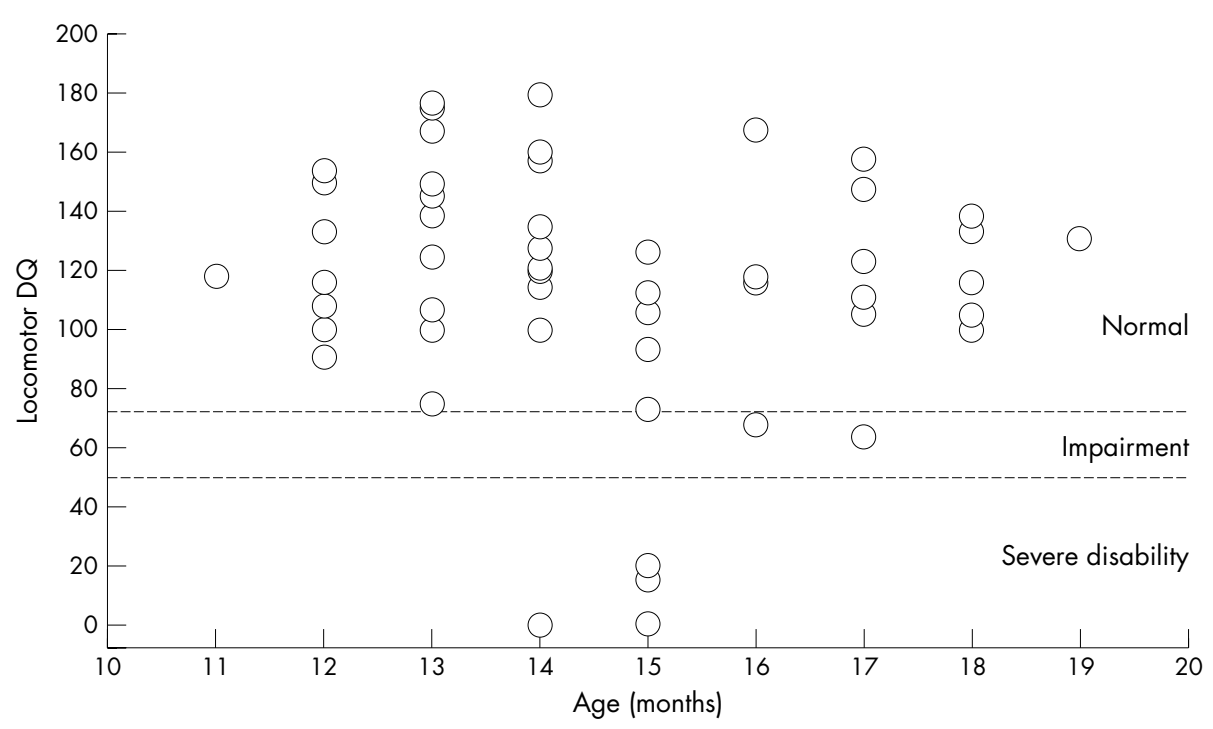

Figure 2 Scatter plot of locomotor developmental quotient (DQ) scores using the schedule for growing skills-II (SGS-II) developmental assessment tool for infants who received follow up $(\mathrm{n}=93)$.

\section{What is already known on this topic}

- ECMO is highly effective at improving survival in neonates with severe respiratory failure, but survivors are at high risk of adverse neurodevelopment

- Alternative means of respiratory support are available for use before ECMO, potentially altering the pattern of ECMO referrals and results

\section{What this study adds}

- New treatments are being used before referral; there is no evidence that this is delaying the time that otherwise eligible infants will receive ECMO therapy

- There is no evidence of an adverse impact on neurodevelopmental outcome during the second year of life

\section{SUMMARY AND CONCLUSIONS}

In the current era, we have found that most term and near term newborn infants with hypoxaemic respiratory failure treated with ECMO have normal neurodevelopment. The zero mortality for MAS indicates that "normal physical and neurodevelopmental outcome" is a realistic aim for all infants with this disorder, particularly as future ECMO recipients may be provided with neuronal cell protection using a "blood cooling" strategy to induce moderate brain hypothermia. ${ }^{13}$ The continued mortality observed in infants with idiopathic PPHN and sepsis and the very poor survival figures for children with $\mathrm{CDH}$ indicate that additional treatments are required to improve outcomes for children with these disorders.

A strategy of early institution of ECMO therapy is likely to result in the best outcomes for newborns with hypoxaemic respiratory failure. ${ }^{14}$ However, at present, there are few markers that predict which infants need ECMO therapy and which can be safely managed with non-ECMO therapies. ${ }^{15}$ At present, our in house criteria for newborns with acute respiratory failure include an OI of $>25$, systemic hypotension requiring treatment with moderate to large doses of inotropes, the presence of air leaks, and cardiorespiratory instability. These criteria may require modification as more outcome data for specific treatments become available. Hence, as recommended by the American Academy of Paediatrics, ${ }^{16}$ we would encourage the collection and publication of data on short and long term outcomes for infants with severe acute respiratory failure on a centre and treatment specific basis.

We acknowledge the care provided by all the staff of the Paediatric Intensive Care Unit, Glenfield Hospital, Leicester to babies referred to the ECMO service.

\section{Authors' affiliations}

K Khambekar, D J Field, Department of Neonataology, University

Hospitals Leicester, Leicester, UK

S Nichani, D K Luyt, G Peek, R K Firmin, H C Pandya, Department of ECMO and Paediatric Intensive Care, University Hospitals Leicester

Competing interests: none declared

\section{REFERENCES}

1 UK Collaborative ECMO Trial Group. UK collaborative randomised trial of neonatal extracorporeal membrane oxygenation. Lancet 1996;348:75-82.

2 UK Collaborative ECMO Trial Group. The UK collaborative ECMO (Extracorporeal Membrane Oxygenation) trial: follow-up to 1 year of age. Pediatrics 1998;101:E1.

3 Beardsmore C, Dundas I, Poole K, et al. Respiratory function in survivors of the United Kingdom Extracorporeal Membrane Oxygenation Trial. Am J Respir Crit Care Med 2000;161:1129-35.

4 Bennett CC, Johnson A, Field DJ, et al. UK collaborative randomised trial of neonatal extracorporeal membrane oxygenation: follow-up to age 4 years. Lancet 2001;7:1094-6.

5 Findlay RD, Taeusch HW, Walther FJ. Surfactant replacement therapy for meconium aspiration syndrome. Pediatrics 1996;97:48-52.

6 Inhaled nitric oxide in full-term and nearly full-term infants with hypoxic respiratory failure. The Neonatal Inhaled Nitric Oxide Study Group. N Engl J Med 1997;336:597-604.

7 Konduri GG, Solimano A, Sokol GM, et al. A randomized trial of early versus standard inhaled nitric oxide therapy in term and near-term newborn infants with hypoxic respiratory failure. Pediatrics 2004;13:559-64.

8 Kinsella JP, Truog WE, Walsh WF, et al. Randomized, multicenter trial of inhaled nitric oxide and high-frequency oscillatory ventilation in severe, persistent pulmonary hypertension of the newborn. J Pediatr 1997;131:55-62.

9 Bellman MH, Lingam S, Aukett A. Schedule of growing skills II: users guide. Windsor: NFER-Nelson, 1996. 
10 Rais-Bahrami K, Short BL. The current status of neonatal extracorporeal membrane oxygenation. Semin Perinatol, 2000;24;406-17.

11 Cook LN. Update on extracorporeal membrane oxygenation. Paediatr Respir $\operatorname{Rev} 2004 ; 5$ (suppl A):s329-37.

12 ECLS Registry Report. Extracorporeal life support organisation, International summary. Ann Arbor, MI: ECLS Registry, July, 2001.

13 Horan M, Ichiba S, Firmin RK, et al. A pilot investigation of mild hypothermia in neonates receiving extracorporeal membrane oxygenation (ECMO). J Pediatr 2004; 144:301-8.
14 Gill BS, Neville HL, Khan AM, et al. Delayed institution of extracorporeal membrane oxygenation is associated with increased mortality rate and prolonged hospital stay. J Pediatr Surg 2002;37:7-10.

15 Kossel H, Baver K, Kewitz G, Karaca S, et al. Do we need new indications for ECMO in neonates pretreated with high-frequency ventilation and/or inhaled nitric oxide? Intensive Care Med 2000;26: 1489-95.

16 American Academy of Pediatrics. Committee on Fetus and Newborn. Use of inhaled nitric oxide. Pediatrics 2000;106:344-5.

\section{IMAGES IN NEONATAL MEDICINE}

\section{Neonate with staphylococcal scalded skin syndrome}

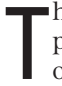
his boy was born after an uncomplicated pregnancy and delivery. On the 5 th day of life, a small blister was seen on the right buttock and thigh. During the course of a few hours, erythema developed on the trunk and blisters in the napkin area. The patient was admitted to our burn centre, and the diagnosis of staphylococcal scalded skin syndrome (SSSS) was made. His vital functions and temperature remained normal. The skin was reddened and painful, with $50 \%$ of the total body area covered by blisters. The Nikolsky sign (separation of the superficial skin from the deeper layers on application of light pressure) was positive. The mucous membranes of the mouth and anus were unaffected. During the next few hours the blisters became more extensive, until they involved $90 \%$ of the total body area (fig 1).

Skin cultures showed a growth of Staphylococcus aureus, which produces exfoliative endotoxin $\mathrm{B}$.

Treatment included administration of intravenous antibiotics and fluid. ${ }^{23}$ The fluid amount was adapted to compensate for evaporation through the large wound surface. Normal body temperature was maintained with extra heat in an incubator, and pain was relieved with intravenous morphine and rectal acetominophen. The wound areas were covered with a polyurethane film (Omniderm). This semipermeable wound cover reduces water permeability and thereby fluid loss. It also creates a favourable environment for epithelisation.

On the third day after admission, epithelisation began and was complete on the 5 th day. The patient was discharged home with intact skin, without scars, seven days after admission (fig 2).

\section{G A Baartmans M H Maas J Dokter}

Medisch Centrum Rijnmond-Zuid, Rotterdam, the Netherlands

Correspondence to: Dr Baartmans, Medisch Centrum Rijnmond-Zuid, Department of Pediatrics, Postbus 9191, Rotterdam 3007AC, the Netherlands; Baartmansm@mcrz.nl mgabaartmans@kabelfoon.n

Competing interests: none declared

\section{REFERENCES}

1 Ladhani S, Joannou CL, Lochrie DP, et al. Clinical, microbial, and biochemical aspects of the exfoliative toxins causing staphylococcal scalded-skin syndrome. Clin Microbiol Rev 1999; 12:224-42.

2 Patel GK, Finlay AY. Staphylococcal scalded skin syndrome. Am J Clin Dermatol 2003;4:165-75.

3 Makhoul IR, Kassis I, Hashman N, et al. Staphylococcal Scalded-Skin Syndrome in a Very Low Birth Weight Premature Infant. Pediatrics 2001;108:el6.

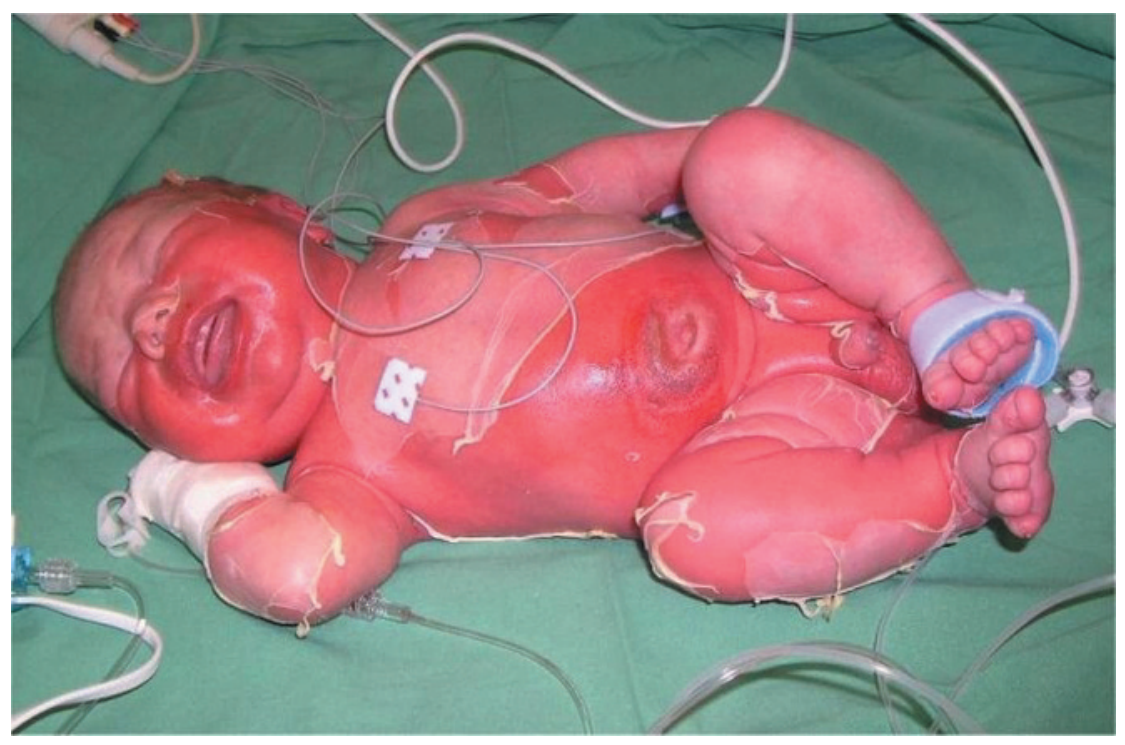

Figure 1 The patient a few hours after the diagnosis of staphylococcal scalded skin syndrome, when $90 \%$ of the total body area was blistered. The child's parents have consented to the publication of this picture.

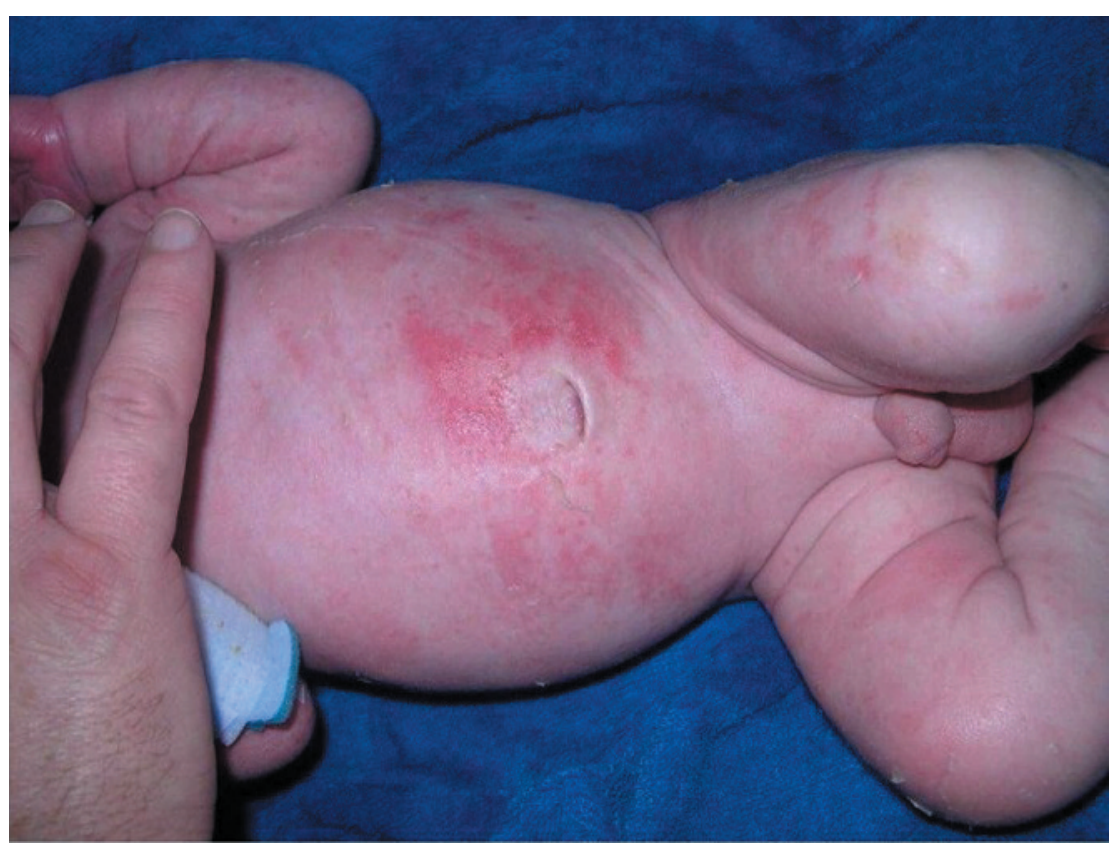

Figure 2 The patient seven days after admission, with intact skin and no scars. The child's parents have consented to the publication of this picture. 